\title{
Charting Access and Inclusion in Future Cities
}

\begin{abstract}
How can access and inclusion become an integral part of the cities of the future? Initiatives such as Smart Dubai hold the answers to making infrastructure investments that deliver economic and social advantage to all of a city's people. This chapter looks at the concept of the "Smart City," namely cities that use decision making, planning, and infrastructure to achieve vastly improved connectivity, efficiency, and access to city services. However, the Smart City also needs to be an accessible city. The Dubai Disability Strategy created a framework for shared governance and measurable progress toward ensuring that Dubai would become an inclusive, rights-based, barrier-free city for people with disabilities. By integrating accessibility standards into the procurement process and standardizing national platforms in line with global access requirements, the government of Dubai can leverage technology to bridge the divide between people with disabilities and those without. The success of the Dubai Strategic Plan and the Dubai Disability Strategy have created a blueprint for inclusive public policy and spurred new initiatives at the federal level. Dubai's local law and strategy is reforming federal institutions. The scaling up of local practices promises to be a catalyst for an even greater commitment to building accessible and inclusive cities across the region.
\end{abstract}

(C) The Author(s) 2020

V. S. Pineda, Building the Inclusive City, https://doi.org/10.1007/978-3-030-32988-4_8 
Keywords Accessibility standards $\bullet$ Bridging the divide $\bullet$ Local law of Dubai $\bullet$ Smart City $\bullet$ Dubai Disability Strategy $\bullet$ Barrier-free $\bullet$ Inclusion - Access to city services $\bullet$ Equity $\bullet$ Connectivity $\bullet$ Efficiency $\bullet$ Local practices $\bullet$ Smart Dubai $\bullet$ Global access $\bullet$ Global cities

\section{Smart City Dubai}

The UAE leadership is united in their understanding that the most important infrastructure investments that cities can make deliver both economic and social advantage to all of its people. Where concrete and roads were once the hallmarks of city development, today citizens demand a far more responsive government, one equitably leveraging the promises of our twenty-first-century digitally connected society. Dubai has made major investments in building out a state of the art program called Smart Dubai to provide improved services, more efficient processes, and greater equity for all, including persons with disabilities.

Investments in more inclusive digital infrastructure result in people being more productive and having access to government services that are more responsive to the needs of citizens. Dubai has also invested considerable resources in becoming the world's "smartest" and now also the most accessible city. In doing so, they may be gaining a competitive advantage over other cities that are slow to implement the technological and policy changes that deliver more connected and empowered people. In listening to city leaders in Dubai and around the world, one key message appears; they are all driven to provide all their constituents with an improved quality of life through better and more personalized services, whether or not they have a disability.

Before we explore Smart Dubai, let's define our key terms. "Smart City" is used to describe the types of infrastructure investments that allow for improved connectivity, efficiency, and access to services within cities. The Smart Cities Council defines a Smart City as one that "uses information and communications technology (ICT) to enhance its livability, workability, and sustainability." ICT includes the full range of modern smart devices, sensors, and software that maximizes the potential of technology to improve the ways that cities operate and for people to access a city's full range of environments and services. Not only do they allow for more efficient operation of city services such as energy or water systems, public transport networks, or public safety, but they are often also the deciding factor on whether persons with disabilities or elderly persons can 
independently utilize a city's services rather than being completely reliant on external assistance, or worse, being forced to remain confined to their homes. Until recently most global discussions on Smart Cities left out persons with disabilities.

Dubai is fully aware of the importance of becoming a recognized Smart City and due to the Dubai disability strategy of 2015, one that is accessible and inclusive. The Smart Dubai initiative was launched by Sheikh Mohammed bin Rashid, Prime Minister of the UAE and Ruler of Dubai, in 2013. The primary aims of the program were to transform Dubai to a Smart City by linking the city's services and improving access to them via smart devices, providing high-speed wireless internet in public locations, and installing a series of sensors throughout the city to provide live information. The program has the lofty aim of making Dubai the "smartest city on the planet," which it will achieve via a mandate that outlines four key pillars and six dimensions.

The four pillars are:

1. Efficient-optimized use of resources

2. Seamless - integrated daily life services

3. Safe-anticipate risks and protect people and information

4. Impactful—enriched life and business experiences for all

The six dimensions are defined as a series of strategic initiatives and partnerships based on improvements across the areas of economy, living, governance, environment, people, and mobility. Note that although neither list prioritizes access or inclusion, there are entry points in the pillars (seamless, impactful) and dimensions (living, people, and mobility).

Both the pillars and dimensions, however, clearly state that the Smart Dubai's aims include improvements in inclusiveness and the life experiences of all citizens. The steps which the program is taking to achieve these goals include hubs that unify government services, a customer experience lab to improve the accessibility of these services, as well as a "happiness meter" voting program to determine people's levels of happiness across different regions within the city on an ongoing basis. The Smart Dubai customer experience program showcases kiosks that feature universal design to ensure the government services kiosks are usable for persons with various types of functional needs.

The Smart Dubai program is a continuation of other innovative programs that have been previously developed and implemented by the Dubai government to drive global competitiveness. These included the Dubai 
Government Excellence Program, launched in 1997, which aimed to prioritize service excellence, as well as the Dubai eGovernment program, launched in 1999 to boost internet penetration in the emirate at a time when global internet penetration was less than 5\%.

The success of programs such as Smart Dubai in effecting the real quality of life improvements for persons with disabilities lies in remaining accountable to the stated aims to improve the life experiences of all citizens, irrespective of if they have difficulty hearing, seeing, remembering, or have challenges with manual dexterity. Metrics are being put in place to accurately show that these improvements are occurring and being used by persons with disabilities and that the programs themselves continue to evolve and follow an iterative, continuous improvement process on inclusive design and usability. Aligning these types of programs with internationally recognized and broadly adopted ICT accessibility frameworks and standards is vital and the Smart Cities for All Global Initiative that I cofounded with my colleague James Thurston is helping cities to become smarter and more accessible.

\section{Bridging the Digital Divide in Inclusive and Smart Cities}

Dubai should have a vested interest in leading the dialogue on the role of technology in building smart, accessible, and inclusive cities. By building in accessibility standards into their procurement process and standardizing digital platforms in line with global access requirements, Dubai is bridging the divide between people with disabilities and those without. Digital accessibility standards like US Section 508 and the European Union's EN 301549 ensure the availability and usability of web and mobile content to all. Although the city and national governments are continuously developing accessibility-related regulation and compliance mechanisms, accessible and inclusive cities can create a market for and incentivize enterprises to bridge the digital divide. Through strong regulations and enforcement mechanisms, Dubai is building an inclusive digital ecosystem with private firms working across the public sector to deliver accessible and inclusive solutions. Companies operating in the UAE now have opportunities to strengthen their accessibility offerings, enabling them to improve the customer experience, appeal to new customer segments, and enter new markets to achieve end-to-end accessible outcomes. 


\section{Design for Humans}

Human-centered design, or inclusive design, is creating a new cultural mindset and engineering approach that initiates and drives the creation of inclusive solutions and digital experiences. Cities and companies that deliver inclusive solutions have a broader and more universal appeal. They provide frictionless experiences and by doing so increase their influence and reach. The power of inclusive thinking is a mindset shift that helps ensure all products and services integrate inclusion and accessibility into city policies, processes, and operations. At a minimum, this requires accessibility training for developers and the active and meaningful engagement of people with disabilities and disability professionals. Microsoft and Apple are also leading the way in inclusive design and incorporating inclusive design practices into public sector solutions.

\section{Artificial Intelligence and the Dubai Future Foundation}

Artificial Intelligence-enabled technologies are creating new interfaces and convergence between assistive and mainstream technologies that can cater to a wide set of needs and abilities, as long as they are trained to be inclusive. Dubai is home to the world's first Museum of the Future, and through the Dubai Future Foundation is leveraging AI to empower people with disabilities. Some areas of interest include assistive robotics; content translation and voice enablement; image and video identification; and mental health.

\section{Workforce Marketplaces, New Industries and Standards}

Cities like Dubai and businesses like Microsoft that have made a commitment to accessibility and inclusion are not merely creating new products and services; they are shaping new marketplaces and even seeding new digital industries. Changes in technology standards, ethical norms, government mandates, and privacy are currently defining the contours of an ecosystem-driven digital economy. Users, customers, and increasingly talent can always move. Cities can opt to exclude a significant segment of the population and can make life more challenging for people with disabilities or they can make intentional steps toward leading the inclusion revolution. 


\section{Inclusive and Accessible Cities of the Future}

Global trends are now demonstrating that technology holds undeniable opportunities for cities that make accessibility an integral part of their digital infrastructure, online services, e-government platforms, and the way they do business. Cities and businesses that prioritize accessibility can experience what Accenture is dubbing the accessibility advantage. This allows them to attract and retain talented workers, develop breakthrough innovations in services, reach new markets and demographics, and keep pace with rapidly evolving accessibility standards in the shifting technological landscape.

For cities to advance their digital inclusion position, they also need to shrink the digital divide and consider these actions:

1. Understand the implications of accessibility on everything they do

2. Celebrate inclusion as a core value

3. Design accessibility into core strategies and measure progress over time

4. Transform urban design and development processes to feature accessibility and inclusion as key components of urban innovation and resilience

5. Build a diverse ecosystem of partners, including local and national linkages and cross-functional task forces continuously advancing policies and programs that advance access and inclusion

\section{Conclusion}

In the past 30 years, a range of structural changes transformed political priorities and put into place some competing ideas of what Dubai was and could be. Starting in 2005, these changes included new approaches that moved disability services from the margins toward the center of planning and social policy. This move also signaled to the world that Dubai was committed to ensuring that the highest standards were met in the provision of public services and that these standards included people with disabilities. This helped to alter the vision of Dubai, bringing into focus the various changes that needed to be made to accommodate a wider range of people who had for too long been excluded from participating in public life. 
Through ratifying the United Nations Convention on the Rights of Persons with Disabilities, 90 countries and many rapidly modernizing cities across the world have taken on this particular challenge. Although Dubai's transformation from a fishing village to a global hub is unique, the city nonetheless must continue to address the need for infrastructure, mobility, and quality public services. In Dubai, as in most cities, unnecessary obstacles prevent people with visual, hearing, or mobility impairments from participating equally in employment, civic, religious, cultural, or family-related activities.

Addressing the needs of people with functional limitations is inherently complex. Disability challenges planners and policymakers to confront difficult urban issues. By sustaining practices that promote social exclusion, planners and policymakers are unwittingly perpetuating unnecessary barriers through outdated practices, policies, or prejudices. Choices in urban design, transportation, housing, and public infrastructure can include or exclude entire populations. Attitudes toward diverse constituents also matter, as they shape and are shaped by the presence or absence of people with disabilities. Within the dynamic and changing forces of globalization, disability rights increasingly embody the progressive ideals of equity, access, and social justice. Planning scholars and practitioners are powerful allies in promoting, protecting, and ensuring that people with disabilities can exercise their rights and participate equally in city life. They play a key role in not only altering the built environment (i.e., removing unnecessary barriers) but also actively promoting the participation of persons with disabilities as a targeted underrepresented group.

When launched by the Government of Dubai's Executive Council in 2015, the Dubai Strategic Plan (DSP) and the Dubai Disability Strategy (DDS) initiated the process of shifting the region's dominant social welfare models of service delivery toward rights-based social development approaches. Doing so reframed the functioning of entire systems and confirmed disability rights and inclusive public policy as a multi-sectoral and cross-functional policy priority. According to many participants I spoke to, it was a journey that involved intense debate and discussion.

Reframing the approach of existing systems required a massive reprogramming and new forms of budget allocations that prioritized social inclusion, social cohesion, and mainstreaming disability in the monitoring and evaluation framework across nearly two dozen government departments. These included reforming policies and programs across education, health, social development, municipal affairs, police and safety, 
sports, social protection, disaster preparedness, and even water and power. The success of the DSP has created a blueprint in inclusive public policy and has spurred new initiatives aligned with the DSP and DDS at the federal level. Dubai's approach to inclusion is scaling up and reforming national institutions. This is creating an even greater commitment from virtually every sector across the UAE. This nation that began as clusters of coastal fishing villages has transformed into a nation of cosmopolitan global cities that espouse and define "inclusive" modernity with a conscience.

When I first arrived in Dubai in 2007, I encountered a city-sized construction zone and a frenzy of developers building the future at any cost. In the subsequent years as I dug deeper, I encountered thoughtful and committed leaders, with a generous spirit inspiring all their people to work hard and claim it. Future-focused cities like Dubai understand that failure to align domestic policies and programs with the broader frameworks like the Sustainable Development Goals (SDGs) or the Convention on the Rights of Persons with Disabilities (CRPD) risks creating norms that fall short of our collective potential. Sheikh Mohammed notes, "What we aspire to create goes beyond the present, and calls upon us to unleash our imagination on what is possible and what we can achieve."

This case study on Dubai was developed to provide evidence and equip scholars and policymakers with new conceptual approaches, empirical evidence, and methodological considerations and to hopefully make a fundamental contribution toward unlocking more inclusive urban futures for the nearly one billion people who live with disabilities. Ultimately, disability is an important demographic, cultural, political, economic, and social reality in the kaleidoscope of urban diversity. A kaleidoscope that allows contemporary planners to not only see but also construct the elusive inclusipe city of tomorrow.

What has been achieved in Dubai in the years between 2015 and 2019 has broadened my imagination of what is possible. When a city plants the seed of accessibility, public perceptions on the importance of equity and inclusion in that city also take hold. Dubai is a unique case study, not by being exceptional or unreplicable but because it illustrates a city's challenges and opportunities, successes, and setbacks. More than anything, however, it demonstrates perseverance in the belief that all people, including persons with disabilities, have the right and the responsibility to help shape our more inclusive urban future. Dubai has embraced the task of transforming its approach and ensuring that this future is accessible to all. 
Open Access This chapter is licensed under the terms of the Creative Commons Attribution 4.0 International License (http://creativecommons.org/licenses/ by $/ 4.0 /)$, which permits use, sharing, adaptation, distribution and reproduction in any medium or format, as long as you give appropriate credit to the original author(s) and the source, provide a link to the Creative Commons licence and indicate if changes were made.

The images or other third party material in this chapter are included in the chapter's Creative Commons licence, unless indicated otherwise in a credit line to the material. If material is not included in the chapter's Creative Commons licence and your intended use is not permitted by statutory regulation or exceeds the permitted use, you will need to obtain permission directly from the copyright holder.

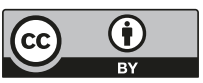

